Marcílio Marques Moreira, exdiplomata, professor universitário,

freqüente conferencista no Brasil e no

exterior, autor de livros e artigos e

também administrador de grupo

financeiro privado nacional.

\title{
O Brasil nos anos oitenta: uma reflexão interdisciplinar
}

\section{Premissas}

Ao contrário do que o fazem supor otimistas panglossianos ou apocalípticos panfletários, a encruzilhada em que se situa o Brasil neste momento crítico, perante desafios internos e exógenos, não tende a conduzir à reedição do 'milagre' ou a colapso explosivo. Ao contrário, é mais provável uma de duas possibilidades: processo paciente, eis que difícil, de institucionalização política, reforma econômica e redistribuição social em regime democrático e, portanto, falível por definição, exigindo determinação, competência e sensibilidade; ou situação insípida marcada por vaivem político sem grandeza, dirigismo estatal sem direção, desempenho econômico mais medíocre do que catastrófico, anomia psicossocial desfibrante e postura indefinida que tente, através de paliativos, obviar tensões sociais mais evidentes.

Esta visão, eqüidistante do alarmismo e da complacência, parte não só de diagnóstico das conjunturas, brasileira e internacional, livre de angústia dramática, senão também de concepção liberal do processo social, a que repugnam certezas meridianas na visão das coisas, tendências persecutórias na sua interpretação ou decisões radicais na sua terapêtica. Apropriam-se, portanto, a esta maneira de ver a realidade, os processos aluvionais de melhoria gradual, a racionalidade econômica temperada por consciência social e o realismo político inspirado por princípios ideais.

\section{OMeio-ambiente externo: problemas eoportunidades}

O mundo, no limiar já quase do terceiro milênio da cronologia cristã, apresenta-se cheio de perigos e de promessas.

Do lado econômico, a estagflação parece configurar-se na crise mais resiliente desde a grande depressão dos anos 30 , e chega mesmo a reviver a teoria dos ciclos longos de Kondratieff ${ }^{1}$, cujo ritmo se repetiria em ondas de aproximadamente cinqüenta anos. Politicamente, não só têm aparecido surtos de terrorismo e de instabilidade interna, senão também guerras localizadas, irracionais ou anacrônicas, como a entre o Iraque e o Irã, o conflito das Malvinas e o drama do Líbano. Socialmente persistem, apesar de inegáveis progressos, desigualdades gritantes em termos relativos e ainda enormes bolsões de pobreza absoluta de que é paradigma o Sahel africano.

Mas, nem tudo é negro nesse quadro. Em primeiro lugar, é preciso ressaltar que, apesar da freqüência e da gravidade dos fenômenos de violência, já estamos há quase quarenta anos do final da última Guerra Mundial2 ${ }^{2}$, que causou perda de vidas na própria guerra, por doença e fome ou por extermínio de massa, em dimensão e características teratológicas tão desproporcionais, que, fugindo à compreensão humana, tendem a ser escondidas em refúgio recôndito da memória. Acresce que o intervalo entre a 1. e a 2. Guerra, período que compreendeu o boom dos anos 20 e o crack dos 30 , durou apenas dois decênios. E apesar das ameaças à détente e da quase- 
psicose de guerra prevalecente em alguns países da Europa, há fortes fatores de paz coalescendo. Os cataclismas de 14 ou de 39 não parecem, pois, prestes a repetir-se, inclusive porque poderiam representar o fim da vida do homem neste planeta.

No plano econômico, os dois choques do petróleo, o chamado choque dos juros, que atingiram níveis nominais e reais inéditos, a desordem do sistema monetário internacional e os déficits públicos crescentes têm criado sérios problemas de inflação e estagnação generalizadas e desequilíbrio profundo do balançc de pagamentos. Esse estado de coisas, tão deplorável que seja, não significa, entretanto, o colapso da economia mundial, a derrocada do sistema financeiro internacional ou a aproximação do fim da civilização ocidental.

A inflação a nível internacional vem apresentando, sob a liderança dos Estados Unidos, sinais de desaceleração acentuada, tendência que parece corresponder a mais aguda consciência política de repúdio ao fenômeno, desagregador direto do valor da moeda e indireto do próprio tecido social, sobretudo quando atinge níveis despropositados e comportamento errático.

A atividade econômica, por sua vez, ainda continua a revelar desempenho decepcionante, alcançando praticamente todos os países. Os da O.E.C.D., que engoloba, além dos Estados Unidos, Japão e Canadá, praticamente todos os países da Europa, devem continuar apresentando, em 1982 e pelo terceiro ano consecutivo, a medíocre média de crescimento de $1 \%$, se não menos. Os da OPEP também sofrerão queda no ritmo de suas economias, dada a redução no volume de produção e nos preços reais do petróleo, devendo, no seu conjunto, registrar o primeiro déficit, ou equilíbrio, nas suas contas correntes, desde 1973. Os países de desenvolvimento intermediário, entre os quais o Brasil, e que abrangem, também, o México, Argentina, Nigéria, Irã, Taiwan, Argélia, Coréia do Sul e Cingapura, haviam mostrado capacidade de resistir melhor do que os países industrializados ou os de menor desenvolvimento relativo ao primeiro choque do petróleo, embora à custa de endividamento crescente, mesmo que exportadores de petróleo, como o México e Nigéria, ou praticamente auto-suficientes, como a Argentina.

Finalmente, os países do quarto mundo estão sofrendo o ônus mais cruel. Com exceção da China, que reformulou sua política econômica, os países do mundo socialista, por sua vez, vêm testemunhando os efeitos crescentes do esclerosamento de suas estruturas econômicas, inclusive pela inexistência de mecanismos de ajustamento a mudanças bruscas de preços relativos, como do petróleo. Acresce-lhes $\mathrm{o}$ anquilosamento do sistema social, a falta de reci- clagem do processo político e o esgotamento da capacidade de formulação e mobilização de suas ideologias-matrizes. Com isto, deteriora-se o nível e a qualidade das informações, indispensáveis à capacidade de resposta de qualquer sistema, e aniquila-se o grau de crítica e de reflexão capazes de induzir à renovação necessária. Tanto é assim, que, ao contrário das sociedades ocidentais, em que a economia central, a americana ainda é a que denota maior vitalidade, no mundo soviético, as economias periféricas, como a Hungria e a Tchecoslováquia, têm apresentado melhor desempenho, pelo arejamento que lhes permitem as ainda estreitas frestas de liberdade que hão conseguido conquistar ${ }^{3}$.

Não obstante esse quadro mundial desalentador, observam-se sinais de melhoria nos Estados Unidos e no Reino Unido que poderá estender-se no segundo semestre de 1983 a outros países europeus. Ao Japão, por sua vez, a economia que realizou o esforço mais sistemático de modernização industrial, melhoria na produtividade energética e aproveitamento dos avanços da informática e robotização, não deverá ser difícil relançar-se, tão logo se recuperem os principais mercados de exportação para seus produtos. Uma vez que ocorrer a sincronização da recuperação, possivelmente na segunda metade de 1983, a retomada provavelmente acelerar-se-á podendo ser mais vigorosa do que previsto.

Quanto aos paises de desenvolvimento intermediário, dependem dos escoadouros para suas exportações e dos níveis de juros. Outrossim, precisam de ajustamentos, abrangentes e de mais longo prazo, o que, em muitos sentidos, extravasa o conjuntural para incluir o repensar a própria estrutura de oferta e de demanda e reorientar as prioridades econômicas que cada sociedade queira eleger.

Quanto aos países do COMECON, perspectivas positivas são mais difíceis de enxergar, não só devido à opacidade dessas sociedades, o que dificulta o conhecimento e a interpretação dos fenômenos, senão também porque qualquer retorno a taxas de crescimento do pós-guerra depende de renovação política e reformulação ideológica, cuja probabilidade a curto prazo parece remota. De qualquer maneira, a própria forma autárquica que escolheram para desenvolver-se, servirá agora de escudo ao inverso para minimizar os efeitos propagadores dessa estagnação. Por outro lado, o surgimento de novas lideranças, talvez precipitado pelo processo de consolidação da sucessão de Brejnev, poderá levar a alguma liberalização, ou, ao contrário, ao retorno a um 'neo-estalinismo', o que parece menos provável.

Se algumas das tendências das economias de mercado acima referidas são antes de natureza conjuntural do que estrutural, elas encobrem mais do que revelam as marcantes mudanças, de natureza 
mais profunda, que estão transformando significativamente o meio ambiente mundial em que o Brasil terá de encontrar o seu próprio caminho nos próximos anos, os últimos do século.

O primeiro desses aspectos refere-se ao leque de experiências de administração econômica que se estão desdobrando, no momento, nos paíseschaves do mundo ocidental.

Parece significativo que, quase simultaneamente, tenham-se esgotado o fascínio e a eficiência de três fórmulas de organização econômica que se projetaram após a Grande Depressão dos anos 30, e sobretudo no pós-guerra, e cujos resultados, até o início dos anos 70, não foi nada desprezível. Trata-se das experiências keynesiana ${ }^{4}$, a do Estado previdenciário e a do planejamento impositivo.

A primeira representou, em grande parte, a resposta capitalista à débâcle de 1930 e, de fato, conseguiu eliminar a contundência econômica dos ciclos econômicos e ainda assegurar, no pósguerra, longo período de crescimento econômico, inflação controlada e melhora nas condiç̃̃es de vida. Embora isto tenha ocorrido, sobretudo nas economias centrais, não há dúvida de que houve razoável movimento de capilarização para a periferia, o que pode ser percebido pela rápida elevação da expectativa de vida no mundo subdesenvolvido como um todo, em apenas quinze anos, o que havia custado setenta anos à Europa do século XIX para atingir.

O crescimento econômico parecia fenômeno tão irreversível que, a partir da segunda metade da década dos sessenta, surgiu reação nos mais diversos setores de opinião contra o fenômeno, que levaria à exaustão inexorável das matérias-primas, à poluição ambiental generalizada, à autodestruição do ecossistema, ou à erosão dos autênticos valoresmorais da civilização ocidental. Era a época da contracultura - de que 1968 foi epítome - dos limites do desenvolvimento, do crescimento zero, da luta ecológica, da desmoralização do próprio conceito de progresso.

Mais forte do que esses movimentos, que, como qualquer iniciativa pioneira, prosperaram graças mais à parcela de verdade que representavam do que às mistificações por que propugnavam, foi a lição da própria realidade: o que parecia um boom sem fim, de repente sofreu freada brusca. O custo muitas vezes acrescido do petróleo e do dinheiro, súbitos movimentos de taxas de câmbio, fenômenos políticos inesperados, medidas econômicas descoordenadas, sistema monetário internacional em aparente estado caótico, a exaustão dos remédios keynesianos, a saturação dos avanços consumistas e o custo insuspeito das próprias conquistas previdenciárias, tudo isso levou à 'inflação crescen- te' cada vez mais mundializada; ao longo periodo de queda do dólar, e à sua espetacular reação posterior; à 'recessão' também abrangente, e ao desemprego que nos países da O.E.C.D. já beira os 30 miIhões de trabalhadores, o maior contigente desde a Grande Depressão. Conduziu, enfim, à estagflação, ao destronamento do keynesianismo e à perplexidade generalizada.

O ouro, relíquia bárbara ${ }^{5}$, mas ainda termômetro sensível, bem reflete esses altos e baixos, eis que de 1971 para cá variou entre 35 dólares por onça a mais de 800 dólares, para nos últimos meses voltar a baixar a menos de 300 , mas reagindo recentemente ao ultrapassar de novo os 400 dólares por onça.

A resposta 'institucional' ao espectro do desemprego dos anos trinta - cuja faceta política nos Estados Unidos foi a longa hegemonia do Partido Democrata e na Europa a supremacia dos regimes social-democratas - consistiu na criação da 'rede de segurança social' pelo Estado do bem-estar, cujo elo principal foi o sistema de previdência pública, em torno do qual passaram a existir, além das aposentadorias e das pensões - que lhe constituem o cerne - o seguro-desemprego, os auxilios à velhice e saúde, os abonos-família, os cupões de alimentação, o amparo à pobreza.

A expansão desses sistemas previdenciários, e dos pagamentos de transferência que ensejam. empurra o Estado a controlar até $50 \%$ da renda interna, alarga os déficits do setor público a nível de até $10 \%$ ou mais do PIB, constituindo-se hoje num dos mais tenazes alimentadores estruturais da inflação. Por essas razões e por também amortecer a produtividade, inibir a inovação e distorcer o processo de alocação ótima de recursos, o welfare słate encontra-se no banco dos réus. Como significou, por outro lado, elemento essencial no resgate da consciência social do liberalismo, ${ }^{6}$ constitui-se em item prioritário no esforço para repensar as estruturas sociopolíticas adequadas para enfrentar o novo turno de modernidade que estamos penetrando.

A terceira experiência que se encontra hoje em dia sub-judice é a do 'planejamento integral', sobretudo o de caráter impositivo, característico dos sistemas de organização econômica do mundo soviético, mas que não se restringe a eles. Essa forma de administrar a economia recebeu impulso ao ser utilizada, com bastante êxito, por ocasião das duas grandes guerras mundiais deste século. O planejamento global que é base da 'economia de guerra' passou, também, a ser crescentemente advogado como o método mais adequado de combate ao subdesenvolvimento, sendo mesmo aceito como tal pelos programas de ajuda dos Estados Unidos.

O fenômeno de fadiga estrutural nos países 
socialistas, cujo dogmatismo acabou conduzindo o sistema sócio-econômico à entropia, aliado à erosão e ao descrédito do estandarte ideológico que o animava, acabou, entretanto, colocando em xeque o próprio método de planejamento estatal rígido e abrangente. Por sua vez, passou a ser criticado naquilo que espelha o gigantismo industrial moderno, contrapondo-se-Ihe os movimentos capilares das células autônomas, das unidades autogeridas, do small-is-beautiful?, enfim da descentralização econômica, social, cultural e política. E como o marxismo-leninismo, pelo seu caráter fechado, não permite processo de crítica, reflexão e recriação, inerente aos sistemas liberais, inclusive os capitalistas, acabou gerando crise mais profunda do que a do mundo ocidental.

Neste, em contraste, competem hoje em dia terapêuticas e interpretações concorrentes: a teoria da economia da oferta dos Estados Unidos, o socialismo pluralista na França, a social-democracia na Alemanha, agora na minoria dada a nova coalizão entre democracia-cristã e liberais. No Japão, fórmula de convivência extremamente engenhosa conseguiu, até agora com êxito surpreendente, conciliar tradição arraigada com tecnologia a mais avançada, articular Estado com iniciativa privada, empresariado e massa operária, embora tenha, até hoje, sido mais feliz na adaptação de tecnọlogia secundária do que no estímulo da criação de tecnologia primária, o que, segundo alguns observadores, pode vir no futuro a comprometer a continuidade de seu dinamismo. Isto sem falar na experiência inglesa que oscila entre o monetarismo ortodoxo e fases de trabalhismo, as experiências sueca ou holandesa e as agora empreendidas em torno do Mediterrâneo, após os movimentos de liberalização política em Portugal, Espanha e Grécia. Há, ainda, a eclética experiência italiana e os ensaios euro-comunistas que, em vários casos, parecem tornar-se mais europeus e menos comunistas.

Experiências paralelas no mundo comunista têm tido que navegar pelas estreitas brechas da liberdade, sob pena de serem esmagadas pela repressão partida de fora ou imposta de dentro, como o experimentaram amargamente a Hungria e Tchecoslováquia e, mais recentemente, a Polônia.

Mas, apesar das dificuldades, angústias e crises, de positivo fica que esmaeceram os modelos sacrossantos e os dogmas infalíveis ${ }^{8}$, em matéria de organização social. Em vez de dicotomias a exigir escolha maniqueísta entre preto e branco, está despontando uma panóplia de experiências as mais variadas, que não devemos copiar servilmente, mas sim estudar com cuidado, para não repetir erros desnecessários ou reinventar acertos evidentes.
Apesar da crise, ou talvez porque em crise, o mundo nos oferece variedade de caminhos, liberdade de escolha, que raramente se nos abriu em outros momentos de nossa história.

A esse leque de alternativas institucionais corresponde riqueza de evolução tecnológica em que se podem lastrear. Os avanços da informática, das comunicações, da biogenética, da robotização e de muitas tecnologias de ponta estão-nos colocando no limiar de nova civilização: pós-industrial, cibernética, tecnotrônica, pós-moderna. Com ela, transformam-se várias premissas da era industrial: a 'uniformidade' que exigia economias de escala crescente e, portanto, o gigantismo industrial; a linha horizontal de montagem cuja superação permite repensar a 'divisão de trabalho', a 'sincronização' dos horários de trabalho, a própria aglomeração em unidades espaciais dos trabalhadores; a mecanização superada pela automação que permite a diversidade e a intervenção mais espontânea do humano; a noção de 'disciplina' industrial imposta pela necessidade de entrosamento de suas diversas engrenagens, a organização do tempo, desde aquele ao longo dos dias, dos anos, o da vida, em formação-trabalho-férias-aposentadoria, as dicotomias estanques casaescola, trabalho-lazer, ou campo-cidade.

Enfim, as oportunidades são muitas; como o são os perigos e as armadilhas. Mas é indispensável que a nossa preocupação natural com o cotidiano, que os desafios inéditos, sérios e absorventes que sejam, não nos distraiam da obrigação de estarmos no posto de escuta da História, para não perdermos mais uma vez a trilha da civilização. Portugal passou ao largo do Renascimento e nós da Revolução Industrial, mas as gerações atuais e as futuras não nos perdoarão se mais uma vez faltarmos ao encontro com o nosso destino.

Em resumo, o mundo em que nos inserimos, e com o qual nos articulamos com intimidade cada vez maior, parece, apesar do enorme ativo representado pela riqueza de sua herança histórico-cultural e do não menor passivo resultante de seu passado colonial, de suas veleidades imperialistas e de-seus aparentes impasses econômicos, 'não' constituir-se em fator 'determinante' de nossas próprias opções. Ao contrário, abre-nos leque amplo de alternativas, formando uma espécie de pano de fundo relativamente neutro em que teremos de inscrever, por decisão e esforço próprio, o 'nosso' caminho. Em outra linguagem, poderíamos dizer que demandas e ofertas externas se equilibram, permitindo-nos traçar o vetor de nossa escolha. Sem desconhecer a realidade mundial, não precisamos ser por ela dominados. 


\section{A Realidade brasileira: desafios e antagonismos}

Embora reconhecendo a autonomia própria das temáticas econômicas, social e política, procurarei abordá-las concomitantemente não só por estar weberianamente convencido do seu estreito entrelaçamento e mútua interação, por processo multifário de afinidades eletivas ${ }^{9} \mathrm{e}$ influências recíprocas, mas sem determinismos univocos, senão também porque a linha de estudos que tenho procurado perseguir tenta seguir fio condutor interdisciplinar. Procura explorar as áreas de sobreposição, repulsae articulação entre aquelas temáticas, e os símbolos de contato fornecidos pela vertente cultural, que constitui uma espécie de linguagem pela qual aqueles vértices da realidade podem comunicar-se, compreender-se e convergir em torno de valores comuns.

Por outro lado, enunciarei mais perguntas do que respostas. O pensamento liberal, a que me filio, não acredita poder distinguir 'o melhor caminho' para os problemas sociais, que apenas aguarda ser 'revelado' por profeta iluminado, técnico erudito ou político esclarecido. Reconhece caminhos alternativos, cujas conseqüências o técnico poderá tentar avaliar, mas cuja escolha será necessariamente de indole política, a ser tomada atendendo às prioridades econômicas que a sociedade postula, aos ditames da ética social e à inspiração da sabedoria pública.

As respostas concretas aos desafios e antagonismos com que se defronta a sociedade surgirão, assim, menos de verdade científica ou de competente fórmula técnica, do que de um gesto de arte política, de um ato de virtude cívica.

Desde 1947, primeiro ano em que a Fundação Getúlio Vargas calculou nossas contas nacionais, 0 Produto Interno Bruto - PIB-brasileiro vem crescendo, em termos reais e cumulativos, a taxa média de $7 \%$. Eembora os dados sobre o período anterior sejam menos confiáveis, as regressões elaboradas a partir de alguns índices, que guardam relação com o desempenho do PIB, indicam que, desde o início do século, a taxa foi de cerca de $5 \%$, extraordinária como nível de crescimento sustentado por tão longo prazo $^{10}$.

Durante os últimos quarenta anos, por outro lado, profundas modificações ocorreram na ordenação espacial e organização social do país. Para dar apenas um dado expressivo, no período de 1940 a 1980, nossa população que era proeminentemente rural, com 2/3 vivendo nos campos e apenas $1 / 3$ na cidade, transformou-se em $2 / 3$ urbanos e apenas $1 / 3$ rural. Isto é, 'em apenas quarenta anos nossa sociedade passou de agrícola-rural para urbana- industrial', processo que na Europa chegou a durar dois séculos. E concomitantemente construiu-se, através da rede de estradas de rodagem, 'um mercado econômico nacional', até então fragmentado em ithas quase autônomas, assim como criou-se, através de rede nacional de televisão, um 'espaço cultural brasileiro'. Ambos os fenômenos só puderam ser implantados, nesse curto prazo, de um lado, pela estrada de rodagem e o caminhão, e, do outro, pelo rádio de pilha e pela televisão, por mais que se pudesse preferir, em retrospecto, ter trilhado as experiências históricas da Europa ou dos Estados Unidos, com a utilização de canais e estradas de ferro, a universalização da escola e do livro.

Essa perspectiva de mais longo prazo parece importante nesse momento crítico de nossa caminhada nacional. Defende-nos contra pessimismo paralisante que poderia levar-nos a acreditar estarmos encurralados por constrangimentos externos e fraquezas internas. Por mais que se saiba que a História não é penhor de destino manifesto que independa das decisões que tomarmos, corretas ou erradas, ela nos ensina a compreender o enorme potencial que nossos antepassados nos legaram, eainda nos entreabre as frestas de um futuro possivel ou mesmo provável, que cabe a nós dirigir. Para $\mathrm{Ma}$ quiavel, deve o homem procurar alargar o espaço de ação de sua virú e estreitar o da forıuna, mera chance ou destino ${ }^{11}$. O retrospecto que traçamos nos ajuda a perceber que, além dos fatores externos adversos e das limitações internas, uma parcela de nossos problemas de hoje decorrem da própria velocidade de nosso crescimento, que acabou atropelando prioridades, estimulando desperdícios e retardando ajustamentos.

Esta maior tranquiilidade que nos transmite a visão histórica permite-nos, pois, perceber a atual 'crise' de nossa economia não como impasse, colapso ou beco sem saída, mas sim no sentido etimológico de sua própria raiz grega sugere: momento de reflexão, diagnóstico, discriminação, discernimento e, sobretudo, decisão. A crise atual tem pois de ser olhada menos como fim de caminho do que como o limiar de 'transformação renovadora'.

Apesar dos cuidadosos exercícios de recálculo empreendidos, é indiscutivel que o Brasil viveu, em 1981, e ainda no primeiro trimestre de 1982, a mais profunda recessão econômica desde a Grande Depressão. De fato, parece lícito afirmar que esta foi a 'primeira recessão industrial moderna da economia brasileira'. De fato, em 30/32, ainda possuíamos uma economia pré-industrial, enquanto em 65/66 nossa indústria, ainda nascente, comparada com a de agora, era de dimensão e complexidade muito menor. Dependendo dos cálculos preliminares ou revistos, a indústria caiu entre $6,5 \%$ e mais de $11 \%$, 
em 1981 e, apesar de sinais de recuperação sentidos a partir de abril de 82, ainda se situa a níveis abaixo da produção de 1980 .

Contrapartida da recessão industrial, a inflação que chegara a $122 \%$ acumulados, no início de 1981, baixou a cerca de $95 \%$ e o déficit comercial que, em 1980, fora de 2,8 bilhões de dólares, passou a superávit de 1,2 bilhões em 1981, embora venha perdendo substâncias em 1982. O grande desafio que se apresenta, agora, às autoridades e à sociedade brasileira, é o de tentar a necessária reversão das tendências recessivas, sem promover pressões inflacionárias compensatórias ou comprometer os ganhos conquistados, a duras penas, no front do comércio exterior. A gestão do processo há de ser prudente e determinada, sem ser prematura ou tardia. Ação precipitada anularia os avanços assinalados em termos de controle de inflação e melhoria da balança comercial. Contemporização poderia representar sério ônus para trabalhadores e empresas, mormente em país como o nosso, que ainda não dispõe de malha social de segurança, isto é, de amortecedores de choques sociais, o que ameaçaria a própria sobrevivência de ambos, e, portanto, o próprio tecido social' ${ }^{12}$.

Talvez porque a profundidade da recessão de 1981 nunca foi reconhecida, a ambigiuidade entre discurso e realidade contribuiu para que os lados positivos da recessão não tenham sido apontados com suficiente clareza, o que poderia ter influido para inversão mais acentuada das expectativas inflacionárias. Agora, torna-se mais difícil a já delicada manobra de resgate do poço recessivo. Acresce que as circunstâncias internacionais que já não eram favoráveis anteriormente para o Brasil, tornaram-se extremamente adversas no curso de 1982. A recessão, especialmente nos Estados Unidos, aprofundou-se além das expectativas e, a partir do último trimestre de 1981, chegou mesmo ao Japão, o país que parecia ter melhor resistido ao segundo choque do petróleo. Os paises de desenvolvimento intermediário, que se haviam transformado em importantes mercados para as exportações brasileiras, especialmente de manufaturados, acabaram atingidos pelo fenômeno. Os preços dos principais produtos primários sofreram quedas violentas, entre eles o café, o açúcar, o cacau e a soja, o que não só nos afetou diretamente, mas também indiretamente, ao prejudicar a balança comercial daqueles países, importadores de nossas manufaturas. $E$, finalmente, as taxas de juros internacionais, tão críticas para o Brasil, em face da alta dívida externa, não apresentaram, no primeiro semestre de 1982, a queda esperada em termos nominais, e dada a marcada baixa da inflação, sobretudo nos Estados Unidos, onde caíram à metade (de cerca de $12 \%$ para $6 \%$ ), elevaram-se, de fato, em termos reais, embora nos últimos meses tenha-se acentuado tendência de queda que deve perdurar em 1983.

Uma certa indecisão na política monetária; níveis de subsídios e gastos governamentais diretos e indiretos ainda elevados, conduzindo a déficit do setor público em patamar entre $5 \%$ e $7 \%$ do PIB; inelasticidade de preços de matérias-primas e de serviços, inclusive de juros internos, preços agrícolas ainda empurrando alguns índices devido a condições regionais climáticas pouco propícias, apesar da boa safra dos alimentos básicos, produtividade deficiente, aumento dos preços de insumos, e pressão sobre a oferta, decorrente da mudança do perfil de demanda induzida pela política salarial; preços industriais em alta não só para compensar compressões passadas, mas também pela elevação de custos unitários de produção resultante da queda do volumee, ainda, descompasso cambial, fruto da alta do dólar, em relação às moedas de outros mercados que constituem os principais escoadouros de nossos produtos de exportação; todos esses fatores parecem ter convergido para deprimir o valor das exportações e para reacender as pressões inflacionárias, exatamente no momento difícil de inflexão internae de agravamento das condições externas.

O horizonte temporal e espacial mais amplo, em que devemos inserir 'o aqui e o agora', protegenos de pessimismo precipitado ou histérico, hipnotizados por indicadores mensais, fragmentários, embora carregados do carisma da verdade mais recente. Não nos exime, contudo, ao contrário, nos obriga a refletir sobre a necessidade de 'estratégia mais abrangente em seu escopo e mais dilatada, em sua perspectiva cronológica'.

Não existe remédio único, milagroso ou simplista para fenômeno tão complexo e arraigado. Entretanto, sem ser uniforme, a terapêutica tem necessariamente de ser de caráter antes global do que isolada, clara e persistente em seus propósitos finais, embora flexível na aplicação à realidade, a cujos sinais tem de se manter atenta. Se apenas medidas isoladas forem tomadas, mesmo que acertadas e severas, o esforço global acabará se esvaindo pelas torneiras ainda abertas, anulando os esforços anteriormente empreendidos, como num trabalho de Sísifo, estéril e infindável.

Impõe-se, portanto, espírito aberto à escuta da realidade, que poderá aconselhar correções de rumo a partir dos resultados alcançados, uma vez mantidas as prioridades políticas que cabe à própria sociedade estabelecer e a coerência interna que os técnicos deverão indicar.

Uma política para procurar atingir, portanto, os objetivos - às vezes contraditórios a curto prazo 
- de combater a inflação, relançar a atividade econômica, reequilibrar as contas externas e, ainda, diminuir os hiatos de renda e da riqueza, que separam regiões e estratos sociais, deverá, portanto, abranger medidas habilmente articuladas, de natureza monetária, fiscal e tributária, de remuneração dos fatores de produção ${ }^{13}$ e de planejamento indicativo das prioridades nacionais.

Sem procurar dirimir a antiga disputa sobre se a política monetária é causa ou efeito, parece fora de dúvida que as pressões inflacionárias envolvendo mudanças de preços, isto é, uma nova relação entre moeda e mercadoria, necessariamente transitam através do comportamento monetário que, ou provocam, ou sancionam a posteriori aquelas mudanças. Em conseqüência, a política monetária deve, no mínimo, comportar-se como elo neutro e, se possível, procurar corroborar - mas não lhe sendo o único instrumento - política econômica mais global.

Aspecto importante dessa abordagem é a política fiscal. É elemento central de qualquer estratégia econômica, além de situar-se na encruzilhada entre as atuações do setor público e privado. Na visão ortodoxa, a articulação entre política monetária e fiscal é mesmo a chave exclusiva do fenômeno inflacionário. Despesas do setor público; tanto de investimento, quanto de gasto corrente, da administração direta e indireta, quando somados a subsídios creditícios ou fiscais, incentivos e transferências, tendem a ultrapassar os ingressos desse mesmo setor público, resultando em déficits sistemáticos ou esporádicos. São esses déficits um dos principais motivos de pressão inflacionária, seja estrutural ou conjuntural. O efeito, entretanto, não é direto, pois depende da maneira pela qual o déficit é financiado. Poderá sê-lo por mera expansão monetária, forma insidiosa de taxação invisível e regressiva, que atinge toda a população indiscriminadamente, ou pela colocação, no mercado, de títulos do Governo a prazos variáveis. A repercussão dessa colocação, por sua vez, depende do nível de poupança interna. A Alemanha e o Japão, apesar dos déficits consideráveis do setor público em relação ao produto interno, tem conseguido financiá-los não inflacionariamente, graças a suas altas taxas de poupança, enquanto nos Estados Unidos déficit como o atual, de apenas 3\% do PIB, deverá corresponder a cerca de $50 \%$ da poupança total disponível. Isto ou obriga o Governo a emitir moeda, ou então o leva a concorrer no mercado de capitais pelas escassas poupanças, elevando a taxa de juros e desestimulando os investimentos privados, com sérias repercussões sobre a taxa de emprego de hoje e a de crescimento amanhã.

No Brasil, o déficit já tradicional do setor público provém de crescimento desordenado desde, atendendo a prioridades pouco definidas, operando a níveis duvidosos de eficiência e sem os controles devidos, com desperdícios evidentes, e onerado por subsídios creditícios e incentivos fiscais. Estes, além de engrossar os déficits públicos, promovem transferências de renda de caráter regressivo. Tiram de muitos para dar a uns poucos, na esperança de que estes poupem, produzam ou exportem mais, o que nem sempre ocorre. Muitas vezes acaba-se estimulando atitudes contrárias às originalmente visadas, incentivando investimentos intensivos em capital e com baixa absorção de mão-de-obra, induzindo a estocagem especulativa de produtos ou de haveres financeiros, permitindo lucros por arbitragens entre financiamentos a taxas aberrantemente diferenciadas e, sobretudo, dificultando a alocação racional de recursos e inibindo o funcionamento dos mecanismos naturais do mercado.

'Política fiscal' austera e realista, não só para controlar o volume agregado de investimentos e gastos, mas também para direcioná-los aos verdadeiros objetivos prioritários, não se esgota evidentemente com o controle de despesas, mas pressupõe o outro lado da moeda, isto é, a arrecadação, suficiente e de forma adequada, de impostos. É a política tributária, propriamente dita, que no Brasil está a exigir profunda reforma, uma vez que a implantada nos idos de 65/67 não só se tornou obsoleta pelas modificações ocorridas desde então na estrutura econômico-social do país, senão também acabou sendo desfigurada por uma série de programas, impostos ou taxas de contribuição posteriormente introduzidos, que mesmo que justificados isoladamente, acabaram formando uma colcha de retaIhos, mal cosida, e que já se constitui hoje em séria deseconomia a empecer o processo de crescimento econômico

Tal reforma precisaria, em primeiro lugar, rever a estrutura espacial do sistema tributário, que acabou centralizando, no governo federal, recursos e responsabilidades de tal ordem, que sua gestão se torna cada vez mais ineficiente. Há, pois, que repensar-se perfil descentralizado, o que deve convergir com movimento de descentralização política, em que o muncípio, muito mais perto das realidades e das demandas das comunidades, ganhe nova autoridade. Seria organização muito mais sistêmica, de círculos concêntricos - Município, Estado, União - o que permitiria maior participação nas decisões de a quem taxar e a quem destinar os recursos arrecadados. O voto distrital, a ser parcialmente introduzido no Brasil, poderá atuar nesse sentido, pois tornará mais visivel a vinculação entre representante e a comunidade que o elegeu.

O sentido de participação a nível comunitário, e até pessoal, seria igualmente reforçado pela maior 
ênfase em impostos diretos onde fica mais transparente a íntima ligação entre contribuinte e cidadão. A 'cidanania tributária', além de permitir efetiva progressividade na escala fiscal, também confere senso de responsabilidade indispensável à participação mais democrática e mais descentralizada nas decisões econômicas, por cuja implantação o cidadãocontribuinte se sentirá mais responsável e solidário.

Tal reforma deverá, também, ter sentido mais igualitário, visando a melhor distribuição dos fluxos de renda, e dos estoques da riqueza. Maior progressividade não significaria necessariamente aumento da carga tributária global, mas maior relevância dos impostos diretos, em vez dos indiretos. Nesse sentido, também haverá de ser estudada, de forma prudente, justa e eficaz, taxação progressiva sobre ganhos de capital e não apenas salário de trabalho, assim como provável imposição sobre sucessões. Esta não deveria ter caráter punitivo, mas deveria acentuar, por estímulo fiscal, a dimensão social da acumulação de patrimônios pessoais. Por exemplo, deveria prever fórmulas que incentivem a criação, já em vida, de fundações de caráter beneficente, científico ou cultural, para estimular as pessoas a construir e legar heranças de interesses também comunitário, a exemplo do que ocorre, por exemplo, nos Estados Unidos ou na França.

Outro aspecto que há de ser ressaltado é a preocupação de estímulo à poupança, ao investimento e à produtividade e de desestímulo aos gastos, sobretudo os supérfluos ou de consumo conspícuo.

Propostas teóricas de impostos progressivos sobre despesas, em vez de sobre a renda, têm sido também formuladas, mas os estudos e experiência não são conclusivos quanto à viabilidade e à eficiência de tal procedimento ${ }^{14}$.

Políticas monetária, fiscal e tributária deverão ser completadas por política geral de ingressos, também chamada de remuneração dos fatores de produção (incomes policy).

Tais políticas têm sido utilizadas, especialmente, em momentos em que fica evidenciada a necessidade de esforço comum envolvendo todos os setores vivos da sociedade, desde o Governo, empresariado, trabalhadores e outros agentes econômicos, entre os quais os consumidores, e segmentos sociais com capacidade de decisão, corno partidos políticos, sindicatos, organizações profissionais ou comunitárias.

O exemplo mais conhecido é o Pacto de Moncloa, firmado depois da queda de Franco, na Espanha, e que permitiu uma trégua nas pressões inflacionárias e reivindicações dos mais diversos setores (preços, salários, juros, tarifas, etc.), formando um lastro mínimo de estabilidade econômica à Espanha de então, indispensável para assegurar a consolidação do processo de liberalização e de redemocratização política ${ }^{15}$.

Embora experiências político-sociais não possam, nem devam, ser transferidas sem muito cuidado e adaptação, há possibilidade e necessidade, no Brasil de hoje, de buscar-se fórmula assemelhada a esta, um entendimento amplo envolvendo os mais diversos setores sociais. Não seria propriamente um pacto social, mas sim um acordo transitório e de objetivos definidos, para permitir a consecução de metas que todos os envolvidos consideram comuns e prioritárias. Como tal entendimento transita através de longa parlamentação política, as eleições de novembro passado poderão facilitar tal processo, pois contribuíram para identificar os interlocutores, adensando-Ihes a legitimidade para falar e comprometer-se, sejam de que partidos forem.

Em contraste, o congelamento de preçose salários, hipótese às vezes aventada, é solução que acaba se transformando em novo problema, porque procrastina providências de mais longo prazo, além de inibir a atuação das leis de mercado, abafando a oferta e estimulando artificialmente a demanda. $\dot{E}$ verdade que às vezes é invocado para corrigir o mau funcionamento dos mecanismos de mercado em situações de monopólio ou oligopólio. Por isso, acredito ser prioritária a recriação e fortalecimento do $\mathrm{CADE}$, que sem mentalidade tacanha ou policialesca, mas com severidade e imaginação, realmente fizesse respeitar no Brasil as regras do livre jogo de mercado, inclusive por parte das empresas estataise das transnacionais. O organismo, além de forte, teria de ser autônomo, subordinado possivelmente ao Poder Legislativo e exercendo poderes quase-judiciais.

Também deveria ser reforçado o Tribunal de Contas da União que, além de função fiscalizatória de caráter contábil, passasse a supervisionar, como uma espécie de corregedoria, a própria eficiência das empresas de Estado e sua atuação nos limites e segundo os objetivos a que se propõem.

De maneira simétrica, o setor privado deveria reforçar os seus órgãos de auto-regulação, a partir de suas associações, que teriam de modernizar-se e tornar-se mais representativas e atentas, não apenas aos interesses dos associados, senão também aos temas nacionais de caráter mais global. Deveriam, igualmente, procurar tornar-se centros de informações setorializadas e macroeconômicas, para que desapareça o atual monopólio da informação econômica no Brasil. Como informação é hoje sinônimo de poder, a descentralização da informação é pré-requisito para a descentralização econômica e política. 
Os temas acima aflorados trazem à baila aquele outro, hoje tão discutido no Brasil, da relação entre setor público e setor privado.

Ao contrário do que pensam muitos, a gravidade do problema não surge do número de empresas, cuja propriedade majoritária se encontra nas mãos do Estado. Embora concordando em que este tenha não poucas vezes exorbitado de suas funções específicas, operando atividades econômicas cuja responsabilidade não lhe cabe, é forçoso, também, reconhecer o papel positivo que o Estado exerceu no Brasil como propulsor de nosso desenvolvimento econômico. E, apesar de considerar que o chamado projeto de desestatização possa e deva transferir às mãos privadas empresas que podem ser administradas pela iniciativa particular, o âmago da questão é outro: a falta de nitidez e confusão na definição das funções de um e outro setor, o que vicia os mecanismos de mercado. 'A preservação da economia de mercado', e não necessariamente a propriedade das empresas que nele atuam, 'é o cerne do problema'. As empresas públicas e as de economia mista - tanto quanto as empresas privadas, brasileiras ou estrangeiras - devem orientar-se, sempre que não estejam em exercício de uma função normativa ou regulatória, ou de prestação de um serviço ou bem de natureza pública, pelas regras de mercado. Indefinição a esse respeito tem levado, inclusive, a fenômeno inverso ao da 'estatização' de funções privadas: a 'privatização' da função pública, quando se procura medi-la ou avaliá-la pelo critério de viabilidade e de retorno privado. Isto pode levar a total desvirtuamento daquela função. Ė, por exemplo, a mentalidade que levou ao atrofiamento dos serviços de saúde pública no Brasil, especialmente os de caráter sanitário, preventivo e comunitário, justamente os que, além de prioritários, apresentam os melhores retornos macroeconômicos e sociais.

Para que uma economia de imercado possa funcionar no Brasil, e para que seja mantida suficiente a vitalidade também noutros campos de atividade, inclusive o cultural, será preciso estender e aprofundar a luta contra a burocracia, que aliada à mentalidade cartorial brasileira, constitui-se hoje em dia em um dos mais sérios entraves ao processo de desenvolvimento, inibindo sobretudo aquele elo que cada vez se torna mais crucial, a 'inovação'. Basta atentar para o número de atividades empresariais que hoje em dia dependem de cartas-patentes, autorizações prévias, concessões pela autoridade do Estado. O mesmo fenômeno ocorre, crescentemente, em relação à regulamentação de carreiras, exigindo diplomas emanados por instituições educacionais rigidamente regulamentadas com currículos prédeterminados. Em um mundo de rápidos avanços científicos e mutações tecnológicas, tal especialização prematura e formalista é desperdício in- desculpável de recursos, talento e imaginação ${ }^{16}$.

Não parece, pois, que o Estado possa, ou mesmo deva, retirar-se de todas funções empresariais em que atua como formentador do desenvolvimento, inclusive da empresa privada. O importante é que, ao fazê-lo, 'não confunda prerrogativa soberana com eficiência empresarial' e que esteja disposto a melhor definir a articulação entre setor público e privado, afastando ambiguiidades e jogos duplos, e deixando de baralhar princípio de mercado, ou jus gestionis, e o de autoridade, ou jus imperii.

Por outro lado, é importante, não só em função dos ditames da justiça social, mas também da eficiência econômica global e da prudência política, que o Estado assuma papel muito mais dinâmico na prestação dos serviços públicos que visem a 'atender às necessidades básicas da população' e na criação de condições para que o setor privado amplie a oferta e abaixe os preços dos bens essenciais de consumo de massa. Penso, em especial, nos serviços de saúde pública, educação, saneamento, nutrição, vestuário e habitação popular. O FINSOCIAL, sem dúvida, é passo na direção certa, embora careça ainda de dimensão global mais abrangente e implementaçăo eficiente.

Fator coadjuvante a recomendar a adoção de tais programas de atendimento às necessidades básicas é que acolhem 'três pré-requisitos' cuja relevância se tornou mais incisiva em face da crise energética, da conveniência de evitar-se que o desemprego se alastre e da ameaça de asfixia cambial. Primeiro, porque são baixos consumidores de energia na sua implantação ou operação; segundo, são pouco intensivos em capital e fortes absorvedores de mão-de-obra, inclusive a não-especializada, e terceiro, não são indutores, em proporção significativa, de importações, tanto na fase de investimento. quanto na de operação, e baseiam-se em tecnologias em geral bem sedimentadas e conhecidas, 0 que dispensa o pagamento de royalties ou facilita a compra de know-how, se necessário, a preços acessíveis.

Quanto aos bens essenciais de consumo, ou 'bens salariais', que seriam predominantemente fornecidos pelo setor privado, também apresentam aquelas características, além de poderem ser produzidos, descentralizadamente, por empresas ou fábricas médias, e, na maioria, de capital nacional, o que minimiza a necessidade de remessa de dividendos. As próprias empresas multinacionais, uma vez bem definidas as prioridades, saberão ajustar-se a elas.

'A economia informal ou submersa', ainda pouco estudada entre nós, mas cuja importância deve ser não desprezivel em termos de geração do PIB e da criação de empregos, é mais vigorosa nes- 
ses ramos de bens salariais, através do trabalho individual ou de mini-empresas. Não deveria ser abafada em benefício de uma legalidade formalística e burocrática, mas no que for possível integrada no chamado 'país legal' e mobilizada para esse esforço de melhoria na qualidade de vida do 'país real'.

Estudos não só realizados aqui, mas no exterior, inclusive pelo Banco Mundial, demonstram a elevada relação benefício-custo de programas de atendimento às necessidades básicas e a sua viabilidade pelo custo relativamente modesto, de dois a cinco por cento do PIB, se o objetivo for atingir toda a população brasileira entre 1990 e o ano 2000 . Comparado ao dos subsídios ou ao somatório de programas de prioridade duvidosa, está perfeitamente dentro das possibilidades de país como o nosso, com renda per capita em torno de 2,000 dólares por ano. Permitiria, praticamente, erradicar os principais bolsões de pobreza absoluta, que ainda englobam de 30 a 40 milhões de brasileiros e que constituem a dívida ética mais séria do que as também não desprezíveis, mas com inteligência gerenciáveis, dividas financeiras externa e interna.

Um só exemplo, extraído de estudo de insuspeito técnico do Banco Mundial, fornece ilustração contundente do muito que precisamos fazer entre nós: "Nesse ano, diz o estudo, 3,8 milhões de crianças nascerão no Brasil. Antes de atingirem um ano, 300 mil morrerão. Se o Brasil tivesse a mesma mortalidade infantil de Sri Lanka, um país cujo PIB per capita é um sétimo daquele do Brasil, 146.000 crianças - pouco menos da metade, deixariam de morrer" $^{\prime \prime} 17$. É clara a dimensão do desafio. É é certo que temos capacidade econômica de enfrentá-lo, bastando para isto senso de prioridade, determinação persistente, compaixão social e racionalidade de meios.

Um último tema merece ser abordado pela atualidade e relevância. $\mathrm{O}$ da relação entre 'democracia', 'desenvolvimento' e 'inflação'. Sem precisar apontar exemplos fora do Brasil, e os há muitos e convincentes, basta voltar à constatação feita, no início, sobre o longo período em que experimentamos crescimento dos mais vigorosos. Se fizermos a desagregação desses períodos e os compararmos aos regimes políticos correspondentes, segundo a sua tônica predominante, democrática ou autoritária, seria difícil constatar correlação estatisticamente significativa entre uns e outros. O mesmo diz respeito à série que registra o comportamento da inflação. Dessa observação empírica, podemos inferir a hipótese, que também é corroborada pela teoria, de que não existe relação de causa e efeito entre democracia, autoritarismo, desenvolvimento e inflação.

Por outro lado, há indicações substanciais de que, a longo prazo, a democracia é forma de organi- zação política mais flexível, que preserva melhor a vitalidade e flexibilidade do tecido social, constituindo-se em sistema superior de governo. Mas, como forma privilegiada de administração política, possibilita uma boa administração econômica, mas não a assegura.

Nessas condições, não há razões para acreditar que o processo de 'liberalização' já percorrido e o de 'democratização' encetado com a realização das eleições de novembro último venham a agravar as pressões inflacionárias ou prejudicar o ritmo de desenvolvimento. Mas o contrário também é verdade. A democracia por si só não garante melhor gestão econômica. Por isso, a par dos temas políticos, há que se discutir também, e urgentemente, as prioridades e métodos econômico-sociais.

Acresce que o fato de o processo de abertura estar desabrochando em momento crítico da conjuntura econômica, não deve servir de argumento para diferir a cronologia ou modificar objetivos da marcha política preconizada. Entretanto, como já referido e, ao contrário do que seria suficiente em época de institucionalização já conșolidada, as circunstâncias brasileiras atuais recomendam, já agora realizadas as eleições, que por natureza são competitivas, que haja busca comum de uma pausa de conciliação ou de convergência nacional (duas palavras-chave da política que radicalismos de direita ou de esquerda tentam desmoralizar) para que possa ser negociado um 'entendimento' sobre algumas prioridades essenciais. Incluiria enumeração de objetivos, fixação de cronologia, rol de eventos e escolha de medidas intermediárias necessárias à consecução dos fins colimados.

Seria uma espécie de trégua nas reivindicações fragmentárias, mesmo que legítimas. A democracia é processo de solução de conflitos, de concorrência entre posições antagônicas e de fixação das regras em que deverá ser travado o jogo entre os diversos atores do processo político. Mas, momentos há na trajetória democrática, sobretudo quando se passa de uma fase mais autoritária para outra mais liberal e participativa, e quando isto ocorre em momento de dificuldades econômicas e tensões sociais, para os quais algo mais é necessário: um 'consenso nacional' envolvendo e engajando todos os agentes dos processos político e econômico: civis e militares, políticos e cidadãos, empresários e trabaIhadores, professores e estudantes, profissionais e consumidores, religiosos e leigos. Consenso que vise a assegurar a compatibilização entre mudança e continuidade, entre liberdade e ordem, entre progresso e justiça.

O hoje e o agora é um desses momentos. 0 que pressupõe sério processo de reflexão, parlamentação e decisão negociada. E que deveria resul- 
tar na elaboração de uma 'estratégia econômica', de realismo, horizonte e abrangência, no mínimo análogos àquelas constantes da 'estratégia política', que, apesar de eventuais dificuldades e pequenos desvios, tem servido para balizar o processo de reinstitucionalização política do país, sem maiores abalos, e com animadora coerência de objetivos.

A decisão do Governo, após algumas hesitações, aparentemente induzidas pelo temor de reações negativas externas e internas, de afinal recorrer ao Fundo Monetário Internacional - F.M.I. -, pontua a 'gravidade da situação econômico-financeira', sobretudo em sua vertente internacional, após o acentuado estreitamento da liquidez mundial decorrente da crise da Polônia, de vários casos de insolvência ou iliquidez de grandes firmas estabelecidas nos países desenvolvidos, da conflagração das Malvinas e das mais recentes situações de inadimplência do México e da Argentina.

Por sua vez, as recentes eleições revelam inclinação do país a favor de líderes e propostas que defendem caminhos eqüidistantes entre mutação extremada e complacência conformista, isto é, procura de mudança na estabilidade. Afastados ressentimentos de vencidos e-arrogância de vencedores, surge, parece, do veredicto das urnas uma vontade de mudar sem ruturas, uma mensagem de renovação mediante métodos e líderes moderados. Pode haver, é claro, excecões mas seria trágico se, a partir dessas, ou de interpretações sibilinas, fragmentárias ou preconceituosas, se quisesse apequenar a voz do povo expressa nas urnas. E sua mensagem, de renovação e moderação, bem ao feitio do caráter brasileiro, e a escolha de novos interlocutores, que podem falar respaldados em legitimidade adensada, convergem para melhorar as probabilidades de êxito desse esforço de aglutinação em torno de ideais e objetivos mais altos e urgentes, que me parece ser o caminho mais prudente a trilhar, a fim de assegurar a transição para um Brasil mais moderno, livre e justo, capaz de, por suas próprias forças, pelo esforço de sua própria gente - trabalhadora e generosa - superar os antagonismos, enfrentar os desafios e aproveitar as oportunidades que nos abrem os dois últimos decênios do século XX.

\section{Notas}

1. Cf. Review, vol. II, n? 4, Spring 1979, publicado por Braudel Center for the Studies of Economies, Historical Systems and $\mathrm{Ci}$ vilizations, State University of New York, Birghanton; número especial dedicado a Cyclical rythms and secular trends of the capitalist world-economy.
2. O que se compara com os quarenta e três anos da 'paz bismarckiana, (entre 1871 a 1914), considerado o período sem guerras mais duradouro da história moderna, embora a partir de 1900 se sentisse claramente o mundo resvalando para o que seria a Primeira Guerra Mundial.

3. O pior perigo para os Estados Unidos, hoje, não parece residir no poderio militar soviético, mas sim no descompasso entre este e a extrema fragilidade da economia russa. De certa maneira, pode-se dizer que os Estados Unidos enfrentam, agora, o desafio de como 'administrar' a fraqueza da União Soviética.

4. Cf. Brian Morgan, Mone'aris's and keynesians - their con'ribu'ion 'o Mone'ary Theory (London: The Macmillan Press Ltd., 1982).

5. A expressão foi cunhada por John Maynard Keynes.

6. Veja a antologia sobre o tema a ser brevemente publicada pe la Universidade de Brasilia sob o título O Liberalismo hoje, tradução do livro comemorativo dos 200 anos da Neue Zürcher Zei'ung.

7. A expressão foi vulgarizada pelo título do livro de Schumacher, que se transformou em bes'-seller.

8. Sobre o dogma existencial-marxista, predominante no pósguerra, veja meu artigo Es'ará o liberalismo obsole'o? publicado em número especial, entitulado O Discurso liberal, da Revista Tempo Brasileiro, de abril/setembro 1981, n? 65/66

9. A expressão foi tomada emprestada por Max Weber, ao clássico romance de Goethe com esse título.

10. Veja, entre outros, Cláudio L. S. Haddad, Crescimento econômico do Brasil 1900-1976 In Paulo Neuhaus, coord. Economia brasileira: uma visão his'órica, Rio de Janeiro: Ed. Campus, 1980, pp. 21 a 43 e Flávio Rabelo Versiani e José Mendonça de Barros, orgs. Formação econômica do Brasil: a experiência da indus'rialização (São Paulo: Saraiva, 1978)

11. O tema é desenvolvido sobretudo em sua obra-prima, $O$ Príncipe.

12. Veja meu artigo anterior em Revis'a do Serviço Público, ano 38, V. $109, n$ : 4 (out . dez. 1981), A Economia brasileira em 1981, esp. pp. 22 e 23.

13. Sobre várias experiências a respeito e sua fundamentação, veja I. L. Fallick e F. R. Elliot, Incomes policies, infla'ion andrelaive pay (London: George Allen E Unwin, 1981).

14. O desenvolvimento do conceito de imposto sobre despesas deve-se, em grande parte, à obra de Nicholas Kaldor. Aliado ao sobre ativos, também advogados por Kaldor e ainda a outras formas de impostos, pode conduzir ao conceito mais abrangente de uma fiscalidade geral ou de um sistema integrado de taxação, que segundo alguns autores pode ser auto-aplicável.

15. Alguns autores falam mesmo dos pactos de Moncloa (no me do Palácio-sede do Governo espanhol), pois houve uma série de entendimentos convergentes. Para o texto do mais conhecido, resultado das reuniōes naquele Palácio de 8 a 9 de ou tubro de 1977, veja Vamireh Chacon, A Experiência espanhola (Brasilia: Universidade de Brasilia, 1979) pp. 81-83.

16. Desenvolvi o tema em minhas Indicacões para o proje'o brasileiro (Rio de Janeiro: Tempo Brasileiro, 1971) esp. pp. 22 a 30.

17. Peter T. Knight, Brazilian socioeconomic development: issues for the eighties In World developmen', vol. 9, n? 11/12 (1981), p. 1071 . 